\title{
DINAMIKA COPING STRESS WANITA DEWASA AWAL YANG MENGALAMI ENDOMETRIOSIS
}

\author{
Indah Ratnayu Adhy Ningsih \\ indah170596@gmail.com
}

\author{
Fakultas Psikologi Universitas Katolik Widya Mandala Surabaya
}

\begin{abstract}
Abstrak
Seorang wanita ketika sudah remaja akan mengalami masa menstruasi. Nyeri menstruasi itu hal yang wajar bagi seorang perempuan. Jika wanita tetap mengalami nyeri yang berlebihan dari yang biasanya, termasuk salah satu dari gejala endometriosis. Rasa sakit yang timbul membuat seseorang akan mengalami stres yang disebabkan penyakit itu sendiri. Untuk menghadapi stres, perlu dilakukan suatu strategi perlawanan yaitu strategi coping stress. Tujuan peneliti untuk mengetahui dinamika coping stress wanita dewasa awal yang mengalami endometriosis. Penelitian ini menggunakan pendekatan kualitatif induktif dengan metode fenomenologi. Informan dalam penelitian ini adalah individu yang terdiagnosa endometriosis. Pengambilan data dalam penelitian ini dilakukan melalui proses wawancara dengan dua informan penelitian. Hasil dari penelitian ini menunjukkan bahwa ketika kedua informan terdiagnosa endometriosis, dampak yang dirasakan kedua informan adalah merasakan stres, cemas dan takut akan rasa sakit yang dialami. Untuk mengatasi stres yang dialami kedua informan, mereka mengeluarkan strategi coping. Bentuk problem focus coping, kedua informan mengatasi sakit dengan cara meminum obat, mengkompres perut dengan air hangat, mengubah pola makan dan gaya hidup. Selain itu, perlakuan emotional focus coping dengan cara mengalihkan ke hal lain seperti sugesti diri sendiri.
\end{abstract}

Kata kunci : endometriosis, nyeri, stress, coping stres, wanita dewasa awal.

\begin{abstract}
When a woman is a teenager, she will experience menstrual periods. Menstrual pain is normal for a woman. If the woman continues to experience more pain than usual, this is one of the symptoms of endometriosis. The pain that arises makes a person experience stress due to the disease itself. To deal with stress, it is necessary to carry out a resistance strategy, namely a stress coping strategy. The aim of the researchers was to determine the dynamics of stress coping in early adult women with endometriosis. This study uses an inductive qualitative approach with phenomenological methods. The informants in this study were individuals diagnosed with endometriosis. Data collection in this study was carried out through an interview process with two research informants. The results of this study indicate that when the two informants were diagnosed with endometriosis, the impact felt by the two informants was feeling stressed, anxious and afraid of the pain they experienced. To deal with the stress experienced by the two informants, they came up with coping strategies. In the form of focus coping problem, the two informants dealt with pain by taking medication, compressing the stomach with warm water, changing diet and lifestyle. In addition, emotional focus coping treatment by diverting to other things such as self-suggestions.
\end{abstract}

Keywords: endometriosis, pain, stress, coping stress, early Adulthood 


\section{Pendahuluan}

Seiring berjalannya waktu, wanita mengalami proses perkembangan anatomi, fisiologis, dan reproduksi. Mulai dari masa anak-anak, kemudian tumbuh menjadi remaja dan dewasa. Selama masa tersebut, wanita mengalami perubahan-perubahan fisik dan perkembangan organ-organ di dalam tubuh. Hal yang paling khas dari seorang wanita yaitu sistem reproduksinya ditandai dengan mengalami masa menstruasi. Menurut Purwoastuti \& Walyani (2015: 58) masa menstruasi adalah merupakan pendarahan akibat luruhnya dinding sebelah dalam rahim. Pengeluaran darah menstruasi bisa berlangsung sekitar 3-7 hari. Ketika menjelang menstruasi wanita akan mengalami kondisi Premenstrual syndrome berupa perubahan emosi, mual, muntah, timbul jerawat dan pusing (Nurhayati \& Wijayanti (2017: 322). Proses ini berlangsung terus sampai berakhirnya masa mestruasi.

Nyeri menstruasi merupakan hal wajar bagi perempuan yang biasanya disebut dismenore. Dismenore akan diklasifikasikan menjadi dua bagian yaitu dismenore primer dan dismenore sekunder. Menurut Prawirohardjo (2011) Dismenore primer yaitu nyeri haid tanpa ditemukan keadaan patologis pada panggul. Biasanya dismenore primer dijumpai di awal bulan atau tahun-tahun pertama menstruasi. Nyeri haid akan pulih dengan sendirinya tepatnya saat hormon tubuh lebih stabil atau perubahan posisi rahim setelah menikah dan melahirkan. Menurut Andrews (2010: 544) dismenore sekunder terjadi pada usia yang lanjut dan dikaitkan dengan gangguan yang didapat, seperti penyakit radang panggul, endometriosis dan adenomiosis.

Konsep sakit atau illness dapat dimaknai sebagai suatu perasaan, persepsi, pengalaman yang bersifat subjektif mengenai keadaan tubuh yang tidak sehat atau tidak enak (Notosoedirjo \& latipun, 2017: 4). Menurut Sarafino (2011: 56) stress merupakan kondisi yang disebabkan oleh interaksi antara individu dengan lingkungan, menimbulkan persepsi jarak
Jika wanita tetap mengalami nyeri yang berlebihan dari yang biasanya itu termasuk salah satu gejala dari endometriosis. Endometrisos sendiri masuk dalam dismenore sekunder yang terjadi karena ada kelainan ginekologi. Menurut European society for Human Reproduction and Embriology (dalam Hendarto, 2015: 5) Endometriosis merupakan terdapat jaringan mirip endometrium berada di luar kavum uteri yang menginduksi reaksi inflamasi kronis. Nyeri dan infertilitas adalah dua gejala klinis yang menjadi keluhan utama penderita endometriosis (Hendarto, 2015: 23).

Menurut Jacoeb \& Hadisaputra (2009: 9) menjelasakan pada umumnya yang mengalami endometriosis pada usia remaja atau wanita usia reproduksi, walaupun tidak menutup kemungkinan endometriosis terjadi pada perimenopause, menopause, dan pascamenopause. Menurut Hurlock (1996: 246) masa dewasa awal dimana dimulai pada usia 18 tahun hingga kira-kira usia 40 tahun memiliki ciri yang menonjol salah satunya usia reproduktif. Menurut Jacoeb \& Hadisaputra (2009: 40) semua keluhan penderita endometriosis penting dicatat dengan cermat, karena endometriosis dapat berdampak terhadap kesejahteraan fisik umum, mental dan sosial seseorang. Menurut Hendarto (2015: 1) Dampak penyakit endometriosis tidak hanya menyebabkan masalah di bidang kesehatan saja, tetapi juga menimbulkan beban berat di sosio-ekonomi masyakat. Dampak tersebut diduga salah satunya penatalaksanaan yang belum efisien yaitu lebih pada pengobatan untuk mengatasi gejala klinis tanpa terapi khusus pada penyebab endometriosis.

antara tuntutan-tuntutan yang berasal dari situasi yang bersumber pada sistem biologis, psikologis dan sosial dari seseorang. Menurut Kiecolt glaser and glaser (dalam Ogden, 2000: 242) menyatakan bahwa stress dapat memperparah penyakit melalui perubahan fisiologis atau sebaliknya stress juga bisa disebabkan karena penyakit itu sendiri. 
Oleh karena itu penyakit dinilai sebagai stress. Berdasarkan dari hasil wawancara dengan informan A menyatakan bahwa mengalami stress ketika dokter mangatakan terdiagnosa endometriosis dan kedepannya akan susah memiliki anak. penjelasan di atas bisa disimpulkan bahwa individu yang memiliki sakit fisik berpotensi untuk mengalami kondisi stress. Untuk menghadapi Stress perlu dilakukan suatu strategi perlawanan yaitu strategi coping stress. Coping suatu upaya dalam mengatasi perubahan kognitif dan perilaku untuk menjalankan tuntutan eksternal dan internal tertentu yang dinilai sebagai beban atau melebihi kapasitas sumber daya orang tersebut (Lazarus dan Folkman, 1984: 141).

Salah satunya penelitian Komalasari dan Septiyanti (2017: 61-65), dari hasil penelitian tersebut bahwa strategi yang lebih sering digunakan oleh wanita menikah yang belum dikarunai anak adalah emotion focused coping dengan presentase sebesar $67,33 \%$. Pada aspek emotion focused coping, strategi yang paling sering digunakan adalah escape avoidance dengan presentase sebesar $14,09 \%$ dan strategi yang paling jarang digunakan oleh wanita menikah dalam menghadapi stress akibat belum dikarunai anak adalah positive reappraisal dengan presentase sebesar $5,85 \%$. Selain itu penelitian yang di lakukan Wahyuni (2008), hasil penelitian ini menjelaskan terjadinya infertilitas karena endometriosis masih belum jelas. Infertilitas endometriosis sangat komplek dan harus mempertimbangkan aspek usia, lama infertilitas, riwayat keluarga endometriosis, nyeri pelvis dan stadium endometriosis. Terapi medikal cukup efektif untuk mengurangi keluhan endometriosis tetapi tidak meningkatkan kemampuan untuk bereproduksi, sedangkan terapi bedah laparoskopi secara signifikan meningkatkan angka kehamilan dan angka kelahiran hidup.

Berdasarkan penjelasan diatas terbatasnya penelitian yang mengungkapkan coping stress wanita yang mengalami endometriosis menyebabkan peneliti ingin mengetahui proses yang terjadi hingga seseorang melakukan strategi coping. Selain itu juga hasil penelitian mengenai endometriosis lebih banyak dibahas di bidang kedokteran.

Tujuan penelitian ini adalah untuk mengetahui dinamika coping stress wanita dewasa awal yang mengalami endometriosis. Manfaat yang di dapat dari penelitian ini adalah untuk memberikan informasi dan memperkaya teori Psikologi Klinis terutama mengenai coping stress. Selain itu, Melalui penelitian ini, para ahli medis yang berhubungan yang mengalami endometriosis mampu memahami kondisi psikologis wanita yang terdiagnosa endometriosis dan mampu memberikan dukungan kepada pasien yang terdiagnosa endometriosis. Penelitian ini juga dapat memberikan gambaran mengenai proses dinamika coping stress dalam mengatasi stress yang dialaminya.

\section{Metode Penelitian}

Pendekatan yang digunakan dalam penelitian ini adalah pendekatan kualitatif. Bursztyn (dalam Hanurawan, 2016: 26) bahwa metode kualitatif untuk mengetahui pengalaman yang terjadi pada manusia. Penelitian tersebut berupa mendeskripsikan dari hasil yang di dapat untuk mengetahui latar belakang motivasi dan perilaku tersebut. Penelitian ini lebih di spesifik pada penggunaan metode fenomenologi. Menurut Giorgi \& Giorgi (dalam Hanurawan, 2016: 83) fenomenologi dapat di artikan sebagai suatu bidang yang mempelajari pemaknaan atas suatu gejala yang terjadi pada ranah individual manusia. Karakteristik partisipan sebagai berikut :

a. Wanita dewasa awal

b. Terdiagnosa dokter endometriosis

Dalam penelitian ini, memperoleh informan menggunakan teknik purposive sampling karena menetapkan pertimbangan-pertimbangan atau kriteriakriteria tertentu yang harus dipenuhi dalam penelitian ini.Hal tersebut di perkuat menurut Sugiyono (2011: 218) purposive sampling adalah teknik pengambilan 
sampel penelitian dengan beberapa pertimbangan tertentu yang bertujuan agar data yang diperoleh nantinya bisa lebih representatif.

Penelitian ini peneliti menggunakan metode wawancara. Menurut Sugiyono (2011: 137) wawancara merupakan teknik pengumpulan data untuk menemukan permasalahan yang diteliti, dan untuk mengetahui hal-hal dari informan secara mendalam dan jumlah informan sedikit atau kecil. Pada metode ini antara interviewer dan interviewee akan berhadapan secara langsung untuk mendapatkan infomasi secara lisan. Jenis wawancara yang dilakukan adalah semi terstruktur. Menurut Wilig (2008: 24) dalam melakukan wawancara membutuhkan persiapan yang matang. Mulai dari memikirkan siapa yang akan diwawancarai, karakteristik informan, menyiapkan untuk merekam dan transkrip hasil wawancara. Dalam proses wawancara peneliti menggunakan alat bantu berupa buku catatan, pedoman wawancara (guideline), alat tulis dan alat perekam suara.

Teknik dalam menganalisis data yang akan digunakan dalam penelitian ini adalah inductive thematic analysis. Menurut Patton (dalam Poerwandari 2013: 45-46) menjelaskan bahwa induktif adalah dimana peneliti tidak membatasi penelitian dan memahami situasi yang terjadi. Menurut Willig (2008: 9), inductive thematic analysis atau istilah lainnya 'big Q' merupakan suatu metodologi penelitian yang berfokus pada mengeksplorasi pengalaman hidup dan makna dari informan dan kemudian bagaimana informan tersebut memberikan makna pada pengalaman tersebut.

Validitas penelitian yang digunakan dalam penelitian ini adalah dengan cara mengecek kembali atau menguji kesahihan data agar terhindar dari bias dalam temuan penelitian. Validitas yang digunakan dalam penelitian ini menurut Sarantakos (dalam Poerwandari, 2013: 208) yaitu : (1) Validitas komunikatif yaitu mengkonfirmasi kembali data dan analisis kepada informan penelitian. (2) Validitas argumentatif yaitu membuktikan dengan melihat kembali pada data mentah atas temuan dan kesimpulan penelitian yang disusun secara rasional. (3) Validitas ekologis yaitu peneliti akan melakukan suatu pengondisian alamiah dari kondisi kesehatan informan yang apa adanya, dan tidak dibuat-buat atau settingan.

\section{Hasil Penelitian}

Dari hasil yang didapatkan, kedua informan melakukan coping stress untuk mengatasi sakit yang dialaminya. Untuk mengatasi kondisi tersebut kedua informan melakukan pendekatan problem focus coping berupa mengatasi dengan minum obat dan mengkompres perut dengan air hangat. Selain itu, informan A cara mengatasi sakit berupa minum jamu, merubah pola makan dan gaya hidup, yoga, meditasi, istirahat dalam kamar, dan menahan terlebih dahulu. Sedangkan infoman $\mathrm{N}$, untuk mengatasi sakitnya datang ke dokter, merubah pola makan, mengikuti saran dokter, dan pijet. Menurut Lazarus \& Folkman (1984: 152-53) Problem focus coping merupakan strategi yang berfokus pada pemecahan masalah. Strategi yang digunakan lebih menekankan pada cara yang digunakan individu untuk menghadapi masalah dan bagaimana usaha yang dilakukan untuk menyelesaikan permasalahan yang dihadapi sebagai upaya untuk menghilangkan situasi dan kondisi yang dapat menimbulkan stres akibat situasi yang penuh tekanan. Usaha lain yang dilakukan kedua informan dengan pendekatan emotional focus coping dengan cara untuk informan $\mathrm{N}$ mengalihkan ke hal lain seperti sugesti diri sendiri. Untuk informan A cara mengatasi stress yaitu tidur, berusaha positive thinking dan menenangkan diri didalam kamar. 


\section{Bagan Hasil Data Pengolahan Kedua Informan}

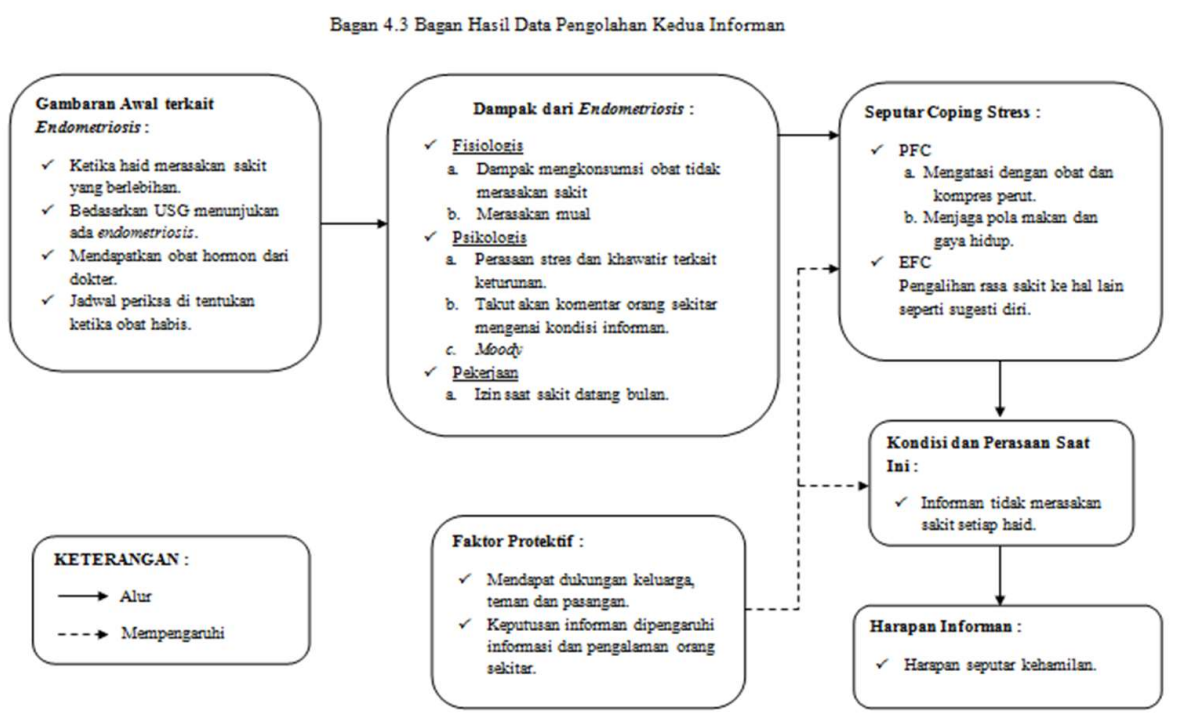

Dalam bagan di atas menjelaskan hasil dari kedua informan mulai dari awal mengetahui terdiagnosa endometriosis melalui hasil USG. Kemudian dampak yang dialami kedua informan dibagi menjadi secara fisiologis berupa ketika diberikan obat tidak mengalami sakit ketika sedang mengalami datang bulan. Secara Psikologis yang dialami stress, khawatir akan keturunan, dan takut komentar akan dirinya jika suatu saat tidak langsung mendapatkan keturunan dan moody. Terakhir dampak dari pekerjaan yaitu ketika sudah tidak bisa menahan rasa sakit yang dialami harus izin kerja dan membuat tugas diberikan kepada teman kerja yang lain untuk menggantikan informan. Dampak yang dirasakan kedua informan tersebut membuat informan melakukan suatu strategi untuk mengatasi. Hal tersebut sejalan menurut Brannon \& Feist (2010: 277) menjelaskan bahwa orang yang mengalami penyakit kronis cenderung melakukan sejumlah strategi coping untuk mengatasi penyakit mereka. Selain itu coping stress juga dipengaruhi oleh beberapa faktor yaitu latar belakang budaya, pengalaman dalam menghadapi masalah, faktor lingkungan, kepribadian, konsep diri, faktor sosial dan lain-lain sangat berpengaruh pada kemampuan individu dalam menyelesaikan masalahnya
(Lazarus dan Folkman, 1984: 158-164). Kedua informan tersebut mendapat dukungan dari keluarga, pasangan dan teman ketika mengalami sakit.

\section{Pembahasan}

Endometriosis merupakan terdapat jaringan mirip endometrium berada di luar kavum uteri yang menginduksi reaksi inflamasi kronis. Nyeri dan infertilitas adalah dua gejala klinis yang menjadi keluhan utama penderita endometriosis (Hendarto, 2015: 23). Berdasarkan data yang didapatkan ketika terdiagnosa endometriosis oleh dokter, kedua informan melakukan berbagai upaya untuk mengatasi sakit yang dialami dan dampak yang didapatkan dari penyakit tersebut. Berdasarkan data yang diperoleh, dapat diketahui bahwa Menurut Brannon \& Feist (2010: 277) menjelaskan bahwa orang yang mengalami penyakit kronis cenderung melakukan sejumlah strategi coping untuk mengatasi penyakit mereka. Menurut Lazarus dan Folkman (1984) fungsi coping dibagi menjadi dua yaitu problem focus coping (berorientasi pada masalah) dan emotional focus coping (berorientasi pada emosi).

Pada informan A ketika terdiagnosa mengikuti saran dokter untuk meminum 
obat hormon untuk mengatasi sakit tersebut. Setelah berapa lama mengosumsi obat tersebut informan mengalami perubahan dari jadwal haid yang teratur selain itu juga perubahan berat badan yang meningkat. Informan A menjelaskan bahwa memutuskan untuk menceritakan juga kepada keluarga keadaan yang dialami dan meminta pendapat keluarga besarnya yang disisi lain kakak iparnya juga seorang dokter umum untuk menyakan perihal sakit tersebut. Dari masukan yang didapatkan informan akhrinya memutuskan tidak mau ke dokter lagi karena berfikir bahwa akan membuat dirinya akan berfikir negatif. Selain itu, informan A memutuskan untuk berhenti meminum obat karena takuk akan ketergantungan pada obat tersebut dan berdampak kepada ginjal dan memutuskan mengatasi sakit dengan mengatur pola makan yang sehat, pola hidup dan pola pikir. Informan A menjelasakan dengan mengubah pola makan seperti makanan yang sehat ( mengurangi makan junk food, memperbanyak makan sayur dan buah) dan pola hidup sehat dampak yang dirasakan mengurangi rasa sakit yang dialami ketika sedang haid dan terkadang informan tidak merasakan sakit ketika haid. Sekarang informan A ketika sakit karena haid lebih menahan rasa sakit tersebut atau beristirahat di kamar saja atau pun selama bisa ditahan tetap melakukan aktifivitas seperti biasa. Ketakutan yang dialami informan A terkait susah mendapatkan anak pun terbantu akan nasehat dan saran yang diberikan orangorang sekitar informan, seperti dari kakak dari pasangannya yang juga sempat susah dikatakan susah memiliki anak karena suatu penyakit dan sekarang akhirnya bisa memiliki anak. Dukungan dari pasangan pun diberikan untuk mengurangi rasa takut dengan mengiatkan makan - makanan yang sehat dan ketika nanti ketika sudah menikah mencoba berobat jika seandainya belum dikarunai anak.

Berbeda apa yang dialmi informan $\mathrm{N}$ ketika terdiagnosa informan sudah menduga yang dialaminya karena faktor informan sekarang sedang mengambil kuliah S2 kebidanan yang ketika di kelas mempelajari mengenai endometriosis. informan $\mathrm{N}$ juga mengikuti saran yang diberikan dokter tersebut dengan mengosumsi obat hormon dan ketika obat tersebut habis informan $\mathrm{N}$ untuk datang konsultasi kembali untuk melihat pekembangan penyakit tersebut setelah mengkonsumsi obat. Dari hasil konsultasi kedua dilihat bahwa hasilnya membaik dari hasil USG dan tidak perlu lagi mengkonsumsi obat hormon tersebut tiap hari. Sekarang informan N ketika mengalami sakit ketika datang bulan mengatasi dengan memberikan koyo di bagian-bagian yang menurut informan sakit dan mengompres perut dengan air hangat untuk mengurangi sakit.

Berdasarkan uraian di atas dapat disimpulkan dari kedua informan melakukan banyak strategi coping stress untuk mengatasi endometriosis yang dipengaruhi oleh berbagai faktor untuk memutuskan suatu hal yang akan dilakukan kedepannya. Hal tersebut sejalan menurut Lazarus \& Folkman (1984: 158-164) faktor yang mempengaruhi cara individu menangani situasi tekanan yang ditentukan oleh sumber daya individu yang meliputi : (a) kesehatan dan energi, (b) keyakinan atau pandangan positif, (c) ketrampilan memecahkan masalah, (d) ketrampilan sosisal, (e) dukungan sosial, dan (f) sumber daya material. Penelitian ini juga menunjukkan adanya faktor kesehatan dan energi, menurut Lazarus dan Folkman (1984: 158-164) merupakan hal yang penting karena dalam usaha mengatasi stres, individu akan membutuhkan kesehatan dan energi untuk bisa menyelesaikan tekanan tersebut. Informan A dan $\mathrm{N}$ ketika merasakan sakit kedua informan tetap beraktivitas. Menurut Lazarus dan Folkman (1984: 158-164), Keyakinan dan pandangan positif yaitu dasar harapan dan yang mendukung upaya penanggulangan dalam menghadapi kondisi yang paling buruk. Harapan dapat didorong oleh keyakinan umum bahwa hasil dapat dikontrol, yang memiliki kekuatan untuk 
mempengaruhi hasil tersebut, Harapan akan ada ketika individu memiliki keyakinan yang membuat hasil yang positif tampak terlihat. Walaupun memiliki keyakinan belum tentu bisa mengatasi tetapi lebih membantu individu untuk menerima situasi yang ada. Dari hasil analisa dari kedua informan terkait sakitnya dipengaruhi dari informasi yang di dapat dan pengalaman orang lain. Selain itu, ada harapan dari kedua informan seputar kehamilan dimana informan A menjelaskan semoga kecemasan yang dialami tidak terjadi dan bisa konsisten menjaga pola makan dan gaya hidup karena itu lumayan berpengaruh berkurangnya rasa sakit. Informan $\mathrm{N}$ berharap segera hamil dalam waktu dekat ini agar informan tidak harus terapi obat karena selama proses terapi berlangsung tidak boleh hamil terlebih dahulu. Ketrampilan memecahkan masalah yaitu kemampuan individu untuk mencari informasi, menganalisis situasi, mengidentifikasi masalah dengan tujuan untuk menghasilkan alternatif tindakan, kemudian mempertimbang alternatif tersebut sehubungan dengan hasil yang ingin dicapai, dan pada akhirnya melaksanakan rencana dengan melakukan suatu tindakan yang tepat menurut Janis dan Mann (dalam Lazarus dan Folkman, 1984 : 162). Dari informan $N$ mendiskusikan kepada pasangan terkait penebalan kembali endometriosis informan $\mathrm{N}$ dan memutuskan untuk pengobatan secara alami dulu jika tidak berhasil baru dengan cara medis.

Menurut Lazarus dan Folkman (1984: 158-164), Ketrampilan sosial merupakan sumber daya penanggulangan yang penting karena peran sosial yang meluas dalam adaptasi manusia. Ketrampilan ini meliputi pada kemampuan untuk berkomunikasi dan bertingkah laku. Informan A dengan menceritakan kecemasanya kepada temannya yang lebih berpengalaman. Dari hasil Analisa kedua informan mendapatkan dukungan sosial dari keluarga, teman dan pasangan dalam menghadapi kondisinya tersebut. Sejalan dengan hasil di atas menurut Lazarus dan Folkman (1984: 158-
164) dukungan sosial Dukungan ini meliputi dukungan dalam memberikan suatu dukungan emosional dan informasi pada diri individu yang didapatkan dari orangtua, anggota keluarga lain, saudara, teman dan lingkungan masyarakat sekitarnya. Terkait Sumber daya material, Lazarus dan Folkman (1984: 158-164) menjelaskan ketika individu memiliki keadaan finansial yang baik, makan hal itu dapat menjadi sumber strategi coping pada individu. Hal itu hasil penelitian dari informan $\mathrm{N}$ yang menyatakan biaya tidak jadi sebuah masalah selama memiliki hasil. Informan $\mathrm{N}$ tidak mempermasalahkan masalah finansial untuk mengobati endometriosis yang dialaminya.

\section{Simpulan dan Saran}

Berdasarkan penemuan yang dilakukan peneliti tentang "Dinamika Coping Stress Wanita Dewasa Awal yang Mengalami Endometriosis”, dapat disimpulkan bahwa banyak variabelvariabel psikologis yang membuat kedua informansi melakukan dinamika coping stress untuk mengatasi endometriosis tersebut. Mulai dari dukungan yang didapatkan dari keluarga, teman, pasangan, sumber daya material, faktor lingkungan, pola hidup, pengambilan keputusan yang di pengaruhi oleh pengalaman orang yang menjadikan terjadinya berbagai coping stress yang dilakukan oleh seseorang.

Dukungan yang didapatkan dari informan berupa pengertian dengan keadaan yang dialami ketika mengalami sakit, nasehat, informasi dan saran untuk membantu informan untuk mengambil keputusan selanjutnya. Selain itu, faktor lingkungan yang terkadang membuat kedua informan tidak nyaman seperti lingkungan sekitar rumah yang yang berpendapat akan hal ketika sakit ataupun seandainya ketika nanti sudah menikah tidak mendapatkan anak. Sumber daya material pun mempengaruhi ketika harus berobat ke dokter dari salah satu informan menjelasakan tidak mempermasalahkan selama itu membuahkan hasil. 
Kedua informan juga berusaha mencari informasi dengan sharing kepada orang lain yang lebih berpengalaman seperti keluarga yang bekerja didunia kesehatan, atau wanita yang pernah mengalami susah memiliki anak. Informasi yang didapat itu yang membuat informan memutuskan hal apa yang akan dilakukan selanjutnya. Berikut ini saran-saran yang diajukan oleh peneliti adalah sebagai berikut :

1. Bagi informan penelitian :

Diharapkan agar kedua informan tetap melakukan coping stress yang telah dilakukan berupa meminum obat untuk meredakan rasa sakit. Selain itu, menjaga pola makan dan gaya hidup agar tidak merasakan sakit setiap masa menstruasi. Sehingga informan dapat bisa mengurangi rasa sakit yang dialami.

2. Bagi keluarga, pasangan dan orangorang terdekat informan :

Dukungan-dukungan positif yang diberikan keluarga, pasangan dan orang-orang terdekat adalah hal yang sangat penting bagi perempuan yang terdiagnosa untuk bisa mencapai coping stress jika tanpa ada dukungan dari semua orang dan memahami kondisi yang dialami informan.

3. Bagi masyarakat umum

Penelitian ini diharapkan mampu menjadi sumber pengetahuan bagi masyarakat mengenai coping stress terhadap penyakit endometriosis.

4. Bagi peneliti selanjutnya :

Penelitian ini dapat menjadi informasi bagi penelitian selanjutnya mengenai dinamika strategi emotional focus coping wanita dewasa awal yang mengalami endometriosis.

\section{Referensi}

Andrews, G. (2010). Buku Ajar Kesehatan Reproduktif Wanita. Jakarta: EGC

Benson, R. C. (2009). Buku Saku Obstetri Dan Ginekologi. Jakarta : EGC
Benson, R. C. \& Pernoll, M. L. (2009). Buku Saku Obstetri Dan Ginekologi Ed 9. Jakarta : EGC

Brannon, L., \& Feist, J. (2014). Health Psychology: An Introduction to Behavior and Health 7 th edition. United States: Wadsworth Cengage Learning.

Desideria, B. (2017). Zaskia Sungkar Jalani Operasi Endometriosis dan Fibroid, Apa Itu?. Tersedia : https://www.liputan6.com/health/rea $\mathrm{d} / 3174018 /$ zaskia-sungkar-jalanioperasi-endometriosis-dan-fibroidapa-itu. Di akses tanggal 04 November 2018. Jam 23.21

Endometriosis Mulai Menyerang Usia Muda . (2009). Tersedia : https://lifestyle.okezone.com/read/20 09/05/21/27/221859/endometriosismulai-menyerang-usia-muda. $\quad$ Di akses tanggal 29 November 2018

Gunawan, I. (2013). Metode Penelitiaan Kualitatif : Teori dan Pratilik. Jakarta: Bumi Aksara.

Hanurawan, Fattah. (2016). Metode Penelitian Kualitatif Untuk Ilmu Psikologi. Jakarta : PT RajaGrafindo Persada

Hendarto, H. (2015). ENDOMETRIOSIS,. Airlangga Universitas Press (AUP)

Hidayah, Nurul. (2007). Identifikasi dan Pengelolaan Stres Infertilitas. Jurnal Humanitas. Vol.4 No.1

Hurlock, E. B. (1996). Psikologi perkembangan: suatu pendekatan sepanjang rentang kehidupan (Edisi ke-5). Jakarta: Penerbit Erlangga.

Jacoeb, T.Z. \& Hadisputra, W. (2009). Penanganan Endometriosis Panduan Klinis an Algoritme. Jakarta : CV. Sagung Seto

Kamus Besar Bahasa Indonesia tentang pengertian ibu. Diakses pada 03 Januari 2019 https://kbbi.web.id/ibu

Kasdu, D. (2005). Solusi Problem Wanita Dewasa. Jakarta : Puspa Swara, Anggota IKAPI

Komalasari, Gantina. \& Septiyanti, Rizka. (2017). Koping Stres Wanita Menikah 
yang Belum Dikaruniai Anak. Jurnal Penelitian dan Pengukuran Psikologi, Vol. 6, No. 2. Dari http://journal.unj.ac.id/unj/index.php/ jppp/article/view/4927. Di akses tgl 25 november 2018 Jam 17.34

Kristanto, A. D. \& Kahija, Y. F. La. (2017). Pengalaman Coping Terhadap Diagnosis Kanker Pada Penderita Usia Kerja Di Rumah Sakit Margono Soekarjo Purwokerto. Jurnal Empati, April 2017 Volume 6 (Nomor 2), halaman $1-9$

Laparoskopi. (Online). Dari https://id.wikipedia.org/wiki/Laparos kopi. Diakses tanggal 25 September 2018

Lazarus, R. S., \& Folkman, S. (1984). Stress, appraisal, and coping. New York: Springer publishing company, Inc

Nurhayati, N. \& Wijaya, R. (2017). Biologi untuk Siswa SMA/MA Kelas XI Kelompok Peminatan Matematika dan Ilmu-ilmu Alam. Bandung : Yrama Widya

Notosoedirdjo, M. \& Latipun. (2017). Kesehatan Mental (Edisi ke-4). Malang : Penerbit Universitas Malang

Ogden, J. (2000). HEALTH PSYCHOLOGY A TEXTBOOK. Philadelphia: Open University Press.

Purwoastuti, T. E., \& Walyani, E. S. (2015). Panduan Materi Kesehatan Reproduksi dan Keluarga Berencana. Yogyakarta : PT. Pustaka Baru

Poerwandari, K. (2013). Pendekatan Kualitatif untuk Penelitian Perilaku Manusia. Depok : LPSP3 Fakultas Psikologi Universitas Indonesia

Prawirohardjo, S., \& Wiknjosastro, H. (2011). Ilmu Kandungan. Jakarta: PT. Bina Pustaka Sarwono Prawirohardjo.

Saktiyono. (2004). IPA Biologi SMP dan MTS jilid 1 untuk kelas VII [Versi Elektronik]. Diambil pada tanggal 30 November 2018 dari http://books.google.co.id/books?id=p FCjM3FTWdgC\&pg=PA30\&dq=ciri $\underline{\text { ciri }+ \text { makhluk }+ \text { hidup\&hl }=\text { en\&sa }=X \&}$ ei=ifYRU8fnPM6IiQeq6IGYDw\&ve

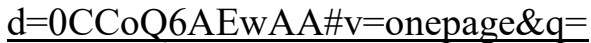
ciriciri $\% 20$ makhluk\%20hidup\&f=fal $\underline{\text { se }}$

Samsulhadi, (2014). Infertilitas Diagnosis Mudahdan Sistem Rujukan, Div. Fertilitas Endokronologi Reproduksi Dept. SMF Obstetri dan Ginekologi, Fakultas Kedokteran Universitas Airlangga

Santrock. (2008). Adolescence. Twelfth edition. New York; The McGraw Hill.Co.Inc

Sarafino, E. P., \& Smith, T. W. (2011). Healty Psychology : Biopsychosocial Interactions $\left(7^{\text {th }}\right.$ ed. $)$. United States Of America : John Willey \& Sonc Inc.

Sugiyono. (2011). Metode Penelitian Kuantitatif Kualitatif dan $R \& D$. Bandung: Alfabeta

Suparman, E. (2012). Penatalaksanaan Endometriosis. Jurnal Biomedik, Volume 4, Nomor 2, halaman : 69-78

Smith, J. A. (2015). Dasar-dasar Psikologi Kualitatif. Bandung : Penerbit Nusa Media

Turangan, L. (2016). Kenali Gejala Penyakit dari Siklus Menstruasi Anda. Tersedia https://lifestyle.kompas.com/read/20 16/08/14/124607323/kenali.gejala.pe nyakit.dari.siklus.menstruasi.anda.

Di akses tanggal 24 September 2018

Triyanto, E. (2010). Hubungan antara Dukungan Suami dengan Mekanisme Koping Istri yang Menderita Kista Ovarium DI Purwokerto. Jurnal Keperawatan Soedirman (The Soedirman Journal of Nursing). Volume 5, No.1. dari https://media.neliti.com/media/ publications/108559-ID-hubunganantara-dukungan-suami-dengan$\underline{\text { me.pdf }}$

Wahyuni, A. (2008). Endometriosis dan Infertilitas. Mutiara Medika Edisi Khusus Vol. 8 No. 1: 62 - 71, April 
2008. Diakses pada tanggal 03 Januari 2019 dari http://journal.umy.ac.id/index.php/m $\mathrm{m} /$ article/view/1647

Wilig, C. (2008). Introducing Qualitative Research In Psychology Second ed. New York : Mc-Graw Hill Open University Press

Windratie. (2015). 25 Persen Pengidap Endometriosis Berpikir untuk Bunuh Diri. https://www.cnnindonesia.com/gayahidup/20150929071317-255-

81494/25-persen-pengidapendometriosis-berpikir-untuk-bunuhdiri. Diakses pada tanggal 29 November 2018. Jam 21.58 World Health Organization. Tersedia di http://www.who.int/reproductiveheal th/publications/guidelines-treatmentinfertility/en/. Di akses pada tanggal 10 November 2018. 